\title{
Differences in psychological and affective well-being between physicians and resident physicians: Does high and low self-regulation capacity matter?
}

Christopher R Simon ${ }^{*}$ and Natalie Durand-Bush

* Correspondence: christopher.r. simon@gmail.com

University of Ottawa, Faculty of Health Sciences, School of Human Kinetics, 125 University Pr., Ottawa, Ontario, Canada, K1N 6N5

\begin{abstract}
Background: Physician well-being has rapidly become an important area of interest given that reduced well-being can have a negative effect on patient outcomes. The majority of studies in this area have focused on impairment, and research on skills and processes that allow physicians and resident physicians to achieve and maintain adequate levels of well-being has been limited. As such, the purpose of the present study was to adopt a positive psychology approach to investigate well-being as more than the presence or absence of dysfunction. It aimed to examine the link between self-regulation capacity, an important self-management skill, and psychological and affective well-being among physicians and resident physicians.
\end{abstract}

Methods: A total of 132 Canadian physicians and resident physicians completed online questionnaires assessing their levels of psychological and affective well-being and self-regulation capacity in order to determine if there were significant differences in well-being between physicians and resident physicians with high and low self-regulation capacity.

Results: Physicians and resident physicians had moderate and high levels of self-regulation capacity, respectively. While both groups were generally high in psychological well-being, they had average levels of positive and negative affect. Between-subject MANOVAs confirmed the hypothesis that high self-regulating physicians and resident physicians have higher levels of psychological well-being and positive affect compared to those with lower levels. However, those higher in self-regulation capacity did not have lower negative affect, nor did physicians have significantly higher levels of psychological and affective well-being than resident physicians.

Conclusions: Results do not support some of the literature suggesting that physicians are highly distressed and cannot manage the demands of their profession. The positive significant association between the physicians and resident physicians' self-regulation capacity and well-being implies that nurturing self-regulation skills within this population could potentially be one way to help them adapt to meet the evolving demands of the medical profession.

Keywords: Psychological well-being; Affect; Positive psychology; Self-regulation capacity; Physician; Resident; Health and wellness

\section{空




\section{Background}

\section{Physician health and well-being: a focus on impairment}

The knowledge and skills physicians derive from years of intensive and committed medical training have prepared them to meet the medical challenges of their patients. However, physicians often lack the skills to effectively manage themselves and their environment (Shanafelt et al. 2003), which could arguably impact their well-being and that of their patients. Although well-being is relevant in any work environment, its importance is underscored in the practice of medicine as this context involves making critical decisions regarding individuals' health (Uncu et al. 2006). Reduced well-being among physicians has been found to have a negative effect on patient outcomes and quality of overall care (Shanafelt et al. 2002; Taub et al. 2006). In response, calls have recently been made to prioritize the health and well-being of physicians (Krasner et al. 2009).

From a research perspective, physician wellness is a rapidly growing field, however, to date, the majority of studies have focused on impairment and dysfunction (Compton 2005), with burnout being the most prevalent theme (e.g., Diez-Pinol et al. 2008; Shanafelt et al. 2003). It is noteworthy that studies on physician well-being often include resident physicians (i.e., physicians undergoing their post-graduate medical education training) as the well-being of this subset of physicians has also become a developing area of interest (Williams et al. 2002). Mirroring the results of studies with physicians, negative outcomes such as burnout (Bragard et al. 2010), stress (Daly and Willcock 2002), and anxiety (Michels et al. 2003) have been observed in resident physicians. Furthermore, low resident wellness has also been associated with reduced quality of patient care (Firth-Cozens and Greenhalgh 1997). Again, similar to their physician counterparts, these negative outcomes have been linked to influencing factors such as lack of sleep and long work hours (Rosen et al. 2006), high expectations (Cohen and Patten 2005), and reduced work-life balance (Eckleberry-Hunt et al. 2009).

Nevertheless, despite inherent nuances between physicians and resident physicians (e.g., level of experience and expertise), it is surprising that few studies have targeted potential differences by comparing and contrasting their levels of well-being. Existing studies tend to focus on single or few wellness-related variables and do not compare the levels of well-being of physicians and resident physicians across multiple dimensions. For instance, it has been shown that resident physicians often have heavier workloads, lower levels of autonomy (Aasland et al. 2008; Biaggi et al. 2003; Thomas 2004), and a higher risk of burnout (Cohen and Patten 2005; Leiter et al. 2009) compared to more senior physicians. In light of such differences between physicians and resident physicians and the scarcity of research comparing the two groups, the present study aimed to assess and contrast the psychological well-being of physicians and resident physicians.

\section{Psychological and affective well-being: a positive psychology perspective}

Although the breadth and depth of physician health and well-being research suggests that a clearer understanding of physician well-being is emerging, it has been argued that little is known about what it means for physicians to be well beyond pathology (Spickard 2001; Weiner et al. 2001). This has led to research demands emphasizing the positive elements of physician well-being (Shanafelt et al. 2005). Consequently, recent movements in positive psychology (e.g., Seligman and Csikszentmihalyi 2000) were followed 
in the present study in order to conceptualize well-being as more than the presence or absence of dysfunction (Haworth and Hart 2007). Two mutually reinforcing conceptualizations of well-being were relevant in the current investigation; psychological and affective well-being.

Ryff and Keyes (1995) put forward a comprehensive, multidimensional perspective of psychological well-being, based on six distinct components of positive psychological functioning:

(a) Positive evaluations of oneself and one's past life (self-acceptance);

(b)A sense of continued growth and development as a person (personal growth);

(c) The belief that one's life is purposeful and meaningful (purpose in life);

(d)The possession of quality relations with others (positive relations with others);

(e) The capacity to manage effectively one's life and surrounding world (environmental mastery);

(f) A sense of self-determination (autonomy).

The extent to which individuals experience these dimensions reflects their overall sense of psychological well-being.

Given the considerable support this multidimensional model has received (Carmody and Baer 2008; Riediger and Freund 2004), and the disproportionate low number of studies that examine physician well-being from a holistic, positive perspective (Spickard 2001; Weiner et al. 2001), the present study on physician and resident physician wellbeing was conceptualized using Ryff and Keyes' six dimensions of psychological wellbeing. Interestingly, although Ryff and Keyes (1995) do not include affect as one of their dimensions in their model, they do not minimize its importance. Since affect plays an important role in one's well-being (Diener 1984; Watson et al. 1988) and in medical practice as well (Wallace and Lemaire 2007), this dimension was also incorporated into the current study. Specifically, affective well-being is characterized by the balance between one's positive (i.e., pleasant emotions) and negative (i.e., unpleasant emotions) affect and one's overall satisfaction with life (Diener and Ryan 2009; Watson et al. 1988).

Although physician well-being has seldom been investigated using an optimal functioning perspective, research in other contexts has consistently demonstrated the positive effect of well-being on different outcomes, which are relevant to the medical profession. Examples include productivity and work performance, quality of social relationships, and mental and physical health (Diener and Biswas-Diener 2008; Keyes and Waterman 2003). Individuals with higher levels of well-being also tend to adopt more positive self-care qualities, and exhibit fewer maladaptive lifestyle and health behaviours (Diener and Ryan 2009; Zimmerman 2000). As such, it seems reasonable to assert that finding ways to help physicians achieve and maintain a high level of well-being may lead to improvements in not only personal health, but also the reduction of medical errors (Goldman et al. 2000) and the overall quality of patient care (Shanafelt et al. 2003). Surprisingly, however, the investigation of such skills, processes, and strategies that may be allowing some physicians to maintain adequate levels of well-being has been limited. To address this gap, the present study explored self-regulation capacity as one such variable. 


\section{Self-regulation capacity}

Self-regulation capacity reflects one's competence to self-manage. It involves planning, generating, controlling, and adjusting thoughts, feelings, and actions in order to achieve personal goals and adapt to one's changing environment. It also takes into account external social agents and the reciprocal effect these have on an individual's behavior (Zimmerman 2000). Self-regulation capacity rests on a series of sub-processes such as goal setting, planning, self-monitoring, and self-reflection (Bandura 1991), which can be developed with attention, effort, and practice (Simon and Durand-Bush 2009). Of interest is that self-regulation capacity addresses not only how we strive for optimal functioning but also how we cope with adversity and dysfunction. In fact, Vohs and Baumeister (2004) reported that many issues we face on a daily basis involve a failure or an inability to effectively self-regulate. Thus, physicians who experience issues related to their well-being may not be effectively self-regulating - that is, managing their behaviours, feelings, and thoughts that resonate with their desired positive outcomes. Conversely, it also stands to reason that physicians who effectively regulate may be more likely to maintain adequate levels of well-being in the face of adversity (e.g., reduced work-life balance, lack of autonomy). Given the central importance of goal-directed behavior in one's self-regulation capacity (Carver and Scheier 1998; Zimmerman 2000) and the link between goal attainment and well-being (Brunstein 1993), it is not surprising that self-regulation capacity has been viewed as a key variable in psychological functioning and linked to a range of positive well-being outcomes (Baumeister et al. 2006; Sanders and Mazzucchelli 2012).

The concept of self-regulation has been extensively studied across multiple contexts including education (Boekaerts and Niemivirta 2000), and health (Leventhal et al. 2003). In education, self-regulation capacity was linked to several positive outcomes. For example, Hofer et al. (2011) found that university students with pronounced self-regulatory capabilities had higher levels of well-being. Park et al. (2012) observed that self-regulation competence was significantly related to positive adjustment (e.g., lower depression, anxiety, and stress) among university students. Moreover, Tangney et al. (2004) demonstrated that students' self-control, a central self-regulation sub-process, predicted low psychopathological symptoms, and better interpersonal relationships. The quality of social relationships is equally important for physicians, as reduced well-being affects the physicianpatient relationship and quality of patient care (Taub et al. 2006). Conversely, a diminished capacity to self-regulate has been linked to negative well-being outcomes. For instance, Hustad et al. (2009) reported that ineffective self-regulation was a risk factor for adverse consequences related to alcohol use among college students. In the context of health, selfregulation capacity has been investigated more as the ability to cope with and adapt to health threats (Leventhal et al. 2003). With a focus on reducing illnesses rather than achieving optimal functioning, it is not in line with the positive psychology approach utilized in the current study. Nonetheless, Leventhal et al. (1998) demonstrated the importance of perception, goals, and social influences in the self-regulation of health threats.

In the context of medical practice, the relationship between self-regulation capacity and the well-being of physicians and resident physicians is virtually unknown. However, three recent studies laid the groundwork for the current investigation. Simon and Durand-Bush (2009) documented the development of self-regulation capacity among medical students participating in a 17-week intervention. Increased capacity was perceived by the students 
to enhance their medical performance. In another study, Sandars and Cleary (2011) postulated that self-regulation competence offers exciting potential for improving academic and clinical performance in medical students. However, its link to well-being outcomes was not discussed. Perhaps the most relevant study to date was conducted by Gagnon and Durand-Bush (2012) who reported that self-regulation capacity was not only significantly correlated with psychological well-being, stress, and burnout in medical students and physicians, it also predicted a significant amount of variance in these outcomes. It was thus concluded that self-regulation capacity might be an important skill for medical students and physicians to develop in order to meet the demands of their medical profession.

\section{Purpose and rationale}

As the evidence suggests, developing effective self-regulatory competence may be a proactive means of addressing dysfunctional outcomes and promoting optimal well-being among physicians and resident physicians. In light of this, and the negative effects the rigors of medical training and practice can have on physician well-being (Musselman 2003; Shanafelt 2008), it is surprising that little research has examined the association between self-regulation capacity and well-being in the context of medicine. In order to shed more light on this, the objectives of this study were to: (a) assess the level of selfregulation capacity and psychological and affective well-being of physicians and resident physicians; and (b) determine if there were significant differences in psychological and affective well-being between physicians and resident physicians with high and low selfregulation capacity. For the first objective, Gagnon and Durand-Bush (2012) found that physicians and medical students had moderate to high levels of self-regulation capacity as well as moderate levels of psychological well-being thus it was hypothesized that physicians and resident physicians in the current study would have the same, that is, moderate to high levels of self-regulation capacity and moderate levels of psychological and affective well-being.

For the second objective, based on the findings of Gagnon and Durand-Bush (2012), it was hypothesized that psychological and affective well-being would significantly differ based on self-regulation capacity levels and the participants' status (i.e., physicians versus resident physicians). Specifically, it was anticipated that those reporting a high capacity to self-regulate would also have a higher level of psychological well-being (Ryff and Keyes, 1995) and positive affect, and a lower level of negative affect (Watson et al. 1988). Furthermore, given that the physicians in Gagnon and Durand-Bush's (2012) study had significantly higher levels of well-being than medical students and given that previous studies have shown differences between physicians and resident physicians (Biaggi et al. 2003; Thomas 2004), it was hypothesized that physicians in the current study would have a significantly higher level of psychological well-being and positive affect and a lower level of negative affect than resident physicians who have less experience and expertise.

\section{Methods}

\section{Participants}

The convenience sample comprised 132 male and female Canadian physicians and resident physicians, who were recruited to also partake in a larger study on physician well-being and self-regulation capacity. All participants were required to be either currently practicing medicine or undergoing residency training. While no other delimitations 
were imposed, the demographics questionnaire revealed that there were twice as more resident physicians $(n=92)$ than physicians $(n=40)$, and there were more women $(n=86)$ than men $(n=46)$. Physicians had an average of 20 years $(S D=10.28)$ of experience, while resident physicians had 2.5 years $(S D=1.5)$. Finally, a range of medical specialties, 26 in total, were represented, the most common being family medicine $(n=34)$, internal medicine $(n=14)$, and obstetrics and gynecology $(n=10)$. Ethics approval for the use of human subjects was obtained through the ethics review board at the University of Ottawa, the institution where the research was conducted.

\section{Data collection procedures}

Provincial associations were contacted via the Canadian Medical Association to request that an e-mail invitation be sent to their members on behalf of the researchers. Seven of ten provinces responded to the call and agreed to do this. The invitation contained general information about the study, ethical procedures, and a web-link to access the questionnaires via a secure website. Further to distributing the recruitment e-mail, many provincial medical associations opted to also advertise the study on their website and in their newsletters. Participation was voluntary and involved responding to online questionnaires that assessed self-regulation capacity, psychological and affective wellbeing, as well as demographic variables. Before responding to the questionnaires, which took approximately 20 minutes, participants were prompted to review the detailed consent form and check a box to provide their informed consent. Although individual data were kept strictly confidential, responses were tracked using a study identification number assigned to each participant for potential participation in the subsequent qualitative phase of the study. The following section provides a brief description of the online questionnaires.

\section{Demographic questionnaire}

This questionnaire was used to describe the demographic characteristics of the sample, including sex, medical specialty, years of practice, province of practice, practice setting (urban or rural), and status (physician or resident physician).

\section{Psychological well-being}

Ryff and Keyes' (1995) Scales of Psychological Well-Being (SPWB) was used to measure psychological well-being. The SPWB comprises six 14-item scales that evaluate psychological well-being across six dimensions: autonomy, environmental mastery, personal growth, positive relations with others, purpose in life, and self-acceptance. The 84 items are evaluated using a 6-point Likert scale ranging from strongly disagree to strongly agree, and generate six scale scores. Example items include: "My decisions are not usually influenced by what everyone else is doing" (autonomy), and "I enjoy making plans for the future and working to make them a reality" (purpose in life). The SPWB has sound psychometric properties and has been used as a comprehensive and reliable measure of well-being in several contexts, including health (e.g., Dukes-Holland and Holahan 2003) and vocational contexts (e.g., Strauser et al. 2008). All six scales have demonstrated excellent internal consistency, with Chronbach's alpha values of .93 (self-acceptance), .91 (positive relations with others), .90 (environmental mastery), .90 (purpose in life), .87 (personal growth), and .86 (autonomy) (Ryff 1989). 


\section{Affective well-being}

The Positive and Negative Affect Schedule (PANAS, Watson et al. 1988) was used to measure affective well-being. With 20 items divided into two 10-item subscales, it assesses how frequently respondents have been experiencing a variety of feelings reflecting positive and negative affect. For example, using a 5-point Likert scale ( 1 = never, $5=$ always), respondents indicate, "To what extent [they] have felt upset during the past few days". Ratings for each subscale are summed, resulting in a total score out of 50 for each subscale. The PANAS has been established as a valid and reliable measure of affective well-being (Miller et al. 2005; Parker et al. 2008) in both health (Voogt et al. 2005) and vocational (e.g., Lent and Brown 2008) contexts. It has also demonstrated excellent internal consistency, with Chronbach's alpha values of .87 for both the positive and negative affect subscales (Watson et al. 1988).

\section{Self-regulation}

In order to assess the participants' general self-regulation capacity (Brown 1998; Miller and Brown 1991), the short version of the Self-Regulation Questionnaire (SSRQ, Carey et al. 2004) was used. Emerging from the original Self-Regulation Questionnaire (SRQ, Brown et al. 1999), the SSRQ is a single factor, 31-item questionnaire scored on a 1 to 5 Likert scale ranging from strongly disagree to strongly agree, yielding a total selfregulation capacity score. An example item is, "I set goals for myself, and keep track of my progress". The SSRQ has been used to measure self-regulation capacity in relation to different health-related variables, from alcohol abuse (e.g., Hustad et al. 2009) to dispositional happiness (e.g., Okun et al. 2009). However nearly all studies to date have been based on undergraduate student populations. The SSRQ has demonstrated excellent internal consistency, with a Chronbach's alpha value of .92 (Carey et al. 2004).

\section{Data analyses}

The data from the online questionnaires were imported into SPSS Statistics Version 20 to verify the internal consistency coefficients of the scales and to compute descriptive statistics and multivariate analyses of variances (MANOVAs). Specifically, internal consistency coefficients were generated for each scale/subscale and an exploratory factor analysis was performed on the SSRQ since it was seldom used in health and vocational contexts. Two between-subject MANOVAs were conducted for the dependent variables of psychological and affective well-being, respectively, to determine whether or not psychological and affective well-being differed as a function of self-regulation capacity (i.e., high and low) and status (i.e., physician and resident physician).

Before conducting the MANOVAs, the SSRQ data was transformed into a categorical variable (i.e., high and low self-regulation capacity). Using a quintile split, the data was recoded into two levels; high self-regulation capacity ( $n=56$; fourth and fifth quartiles), and low self-regulation capacity ( $n=51$; first and second quartiles), accounting for $42.4 \%$ and $38.6 \%$ of the data, respectively. Scores from the third quartile $(n=25)$ were discarded in order to adequately distinguish between high and low self-regulation capacity.

Based on Tabachnick and Fidell's (1996) recommendations to determine sample size, an adequate number of participants were included in this study to conduct the MANOVAs as there were more cases in every cell than the number of dependent variables. 
Nevertheless, Pillai's Trace was used to report the multivariate tests in lieu of the more common Wilks' Lambda as it is more robust and preferred when cell sizes are unequal (Garson 2012).

\section{Results}

\section{Internal consistency and exploratory factor analysis}

The SPWB scales had acceptable internal consistency coefficients, with Cronbach's alpha values ranging from .91 (excellent) to .82 (good) (George and Mallery 2003). Both PANAS subscales were also internally consistent with alpha values of .92 (excellent) for positive affect, and .80 (good) for negative affect (see Table 1). Given the implicit conceptual similarities between psychological and affective well-being, it is noteworthy that issues related to collinearity between the SPWB and PANAS were deemed unlikely due to the Pearson correlation coefficients of .67 and -.47 for positive and negative affect, respectively, with psychological well-being (based on an average total score derived from all six scale scores).

Although the SSRQ was the most conceptually relevant and psychometrically valid self-report measure available to assess general self-regulation capacity (Carey et al. 2004), it had seldom been used in a medical context prior to the current study. Therefore, an exploratory factor analysis (EFA) using a forced one-factor solution (principal component analysis extraction method) was conducted to verify if Carey et al.'s (2004) 31-item single factor could be reproduced with this population. Using the same criterion as that in the original SSRQ psychometrics evaluation (Carey et al. 2004), items loading below .4 were removed over a six-step recursive process, at the end of which all items loaded above this value and additional item removal failed to increase the variance.

Of the original SSRQ items, 12 were dropped leaving 19 items with a total variance of $31.8 \%$ explained. Although the total variance explained was nearly $11 \%$ lower than the $43 \%$ reported by (Carey et al. 2004), it was decided that removing additional items would compromise the conceptual integrity of the original SSRQ (Carey et al. 2004).

Table 1 Descriptive statistics and Cronbach's alpha values for self-regulation capacity, psychological well-being, and affective well-being

\begin{tabular}{|c|c|c|c|c|}
\hline \multirow[b]{2}{*}{ Variable } & \multicolumn{2}{|l|}{ Overall } & \multirow{2}{*}{$\begin{array}{l}\text { Physician } \\
M(S D)\end{array}$} & \multirow{2}{*}{$\begin{array}{l}\text { Resident } \\
M(S D)\end{array}$} \\
\hline & $M(S D)$ & $a$ & & \\
\hline Self-Regulation Capacity ${ }^{a}$ & $72.28(8.65)$ & .87 & $69.73(7.85)$ & $73.39(8.79)$ \\
\hline \multicolumn{5}{|l|}{ Psychological Well-Being ${ }^{b}$} \\
\hline Personal growth & $68.82(7.57)$ & .85 & $68.66(8.43)$ & $68.89(7.2)$ \\
\hline Purpose in life & $68.80(8.96)$ & .89 & $66.92(9.13)$ & $69.67(8.8)$ \\
\hline Positive relations with others & $66.64(10.65)$ & .91 & $65.37(11.53)$ & $67.23(10.23)$ \\
\hline Self-acceptance & $65.55(10.73)$ & .91 & $65.42(10.92)$ & $65.61(10.7)$ \\
\hline Autonomy & $60.22(8.76)$ & .82 & $61.13(7.85)$ & $59.80(9.17)$ \\
\hline Environmental mastery & $59.73(10.42)$ & .89 & $61.42(10.2)$ & $58.95(10.48)$ \\
\hline \multicolumn{5}{|l|}{ Affective well-Being ${ }^{c}$} \\
\hline Positive affect & $33.60(8.49)$ & .92 & $33.84(9.21)$ & $33.48(8.19)$ \\
\hline Negative affect & $17.94(5.25)$ & .80 & $16.58(5.47)$ & $18.59(5.04)$ \\
\hline
\end{tabular}

Note. $M=$ Mean; $S D=$ Standard Deviation; $a=$ Cronbach's Alpha Value.

${ }^{a} n=132$.

${ }^{b} n=120$.

${ }^{c} n=117$. 
The Kaiser-Meyer-Olkin measure of sampling adequacy was .826, above the recommended > .500 (Cerny and Kaiser, 1977), and Bartlett's test of sphericity was significant $\left(x^{2}=885.68, p<.001\right)$, indicating favorable factorability. Cronbach's alpha (.87) demonstrated favorable internal consistency, but was slightly lower than the .92 value found by Carey et al. (2004) with the original 31-item SSRQ. The scores from the revised 19-item SSRQ $(n=132)$ fell within an acceptable normal distribution range (Skewness, -.099; Kurtosis, -.300). In light of the exploratory nature of this study, the lack of conceptually relevant tools measuring general self-regulation capacity, and the acceptable psychometric properties of the revised 19-item version of the SSRQ, the latter was used to assess the level of self-regulation capacity of physicians and resident physicians.

\section{Descriptive statistics}

All data were normally distributed. Means, standard deviations, and Cronbach's alpha values $(\alpha)$ from the 19-item SSRQ $(n=132)$ (revised from Carey et al. 2004), the SPWB $(n=120)$ (Ryff and Keyes 1995), and the PANAS $(n=117)$ (Watson et al., 1988) are provided in Table 1 .

It is likely that differences in the sample sizes are attributable to the temporal order in which the respondents were prompted to complete the three questionnaires. Some chose to exit the website without responding to the remaining questionnaire(s). Thus, while all participants in the study responded to the SSRQ (ordered first), twelve exited after completing the SPWB (ordered second) and omitted the PANAS (ordered third), and 15 only responded to the SSRQ, omitting both the SPWB and PANAS. No participants who exited the survey early asked to have their data withdrawn from the study.

\section{Levels of self-regulation capacity and psychological and affective well-being}

The SSRQ was evaluated using a possible total sum score varying from 19 to 95, wherein the higher the score, the higher the level of self-regulation capacity. Physicians $(n=40)$ reported a mean scale score of $69.73(S D=7.85)$ while resident physicians $(n=92)$ reported a mean scale score of $73.37(S D=8.79)$. One way to delimit high, moderate, and low selfregulation capacity was to adapt the cut-off scores reported by Brown et al. (1999) ${ }^{\text {a }}$. Based on these, $45 \%(n=18)$ of physicians and $62 \%(n=57)$ of resident physicians had a high level of self-regulation capacity. In contrast, $32 \%(n=13)$ of physicians and $16.3 \%(n=15)$ of resident physicians had moderate levels, and finally $22.5 \%(n=9)$ of physicians and $21.7 \%(n=20)$ of resident physicians reported low levels of self-regulation capacity.

With respect to psychological well-being, each individual PSWB scale was evaluated using a possible total sum score ranging from 14 to 84 , whereby the higher the score, the higher the well-being for that specific dimension. Physicians $(n=38)$, on average, obtained the highest mean on purpose in life $(M=66.92 ; S D=9.13)$ and personal growth $(M=68.66 ; S D=8.43)$, and the lowest on environmental mastery $(M=61.42$; $S D=10.20)$. On the other hand, resident physicians $(n=82)$ scored highest on purpose in life $(M=69.67 ; S D=8.8)$ and personal growth $(M=68.89 ; S D=7.2)$ like their physician colleagues, but they equally scored high on positive relations with others $(M=$ 69.67; $S D=8.80$ ). Like physicians, they scored the lowest on environmental mastery $(M=58.95 ; S D=10.48)$ (see Table 1$)$. Due to the lack of available norms or suggested ranges, psychological well-being was delimited using quartiles based on the SPWB minimum (14) and maximum (84) scores ${ }^{\mathrm{b}}$. Based on these parameters, both physicians 
and resident physicians had high levels on all dimensions of psychological well-being, with the exception of environmental mastery whereby resident physicians obtained a moderately high level that was just below the high level cut-off score.

In terms of affective well-being, the positive and negative affect subscale scores on the PANAS were each evaluated using a mean of the total possible sum scores ranging from 10 to 50. Physicians $(n=38)$ obtained a mean positive affect score of 33.84 $(S D=9.21)$ and a mean negative affect score of $16.58(S D=5.47)$. In comparison, resident physicians $(n=79)$ had a mean positive affect score of $33.48(S D=8.19)$, and a mean negative affect score of $18.59(S D=5.04)$. According to classification procedures adapted from Peeters et al. $(1996)^{\mathrm{c}}$, both physicians and resident physicians had moderate levels of both positive and negative affect.

\section{Multivariate analyses}

Table 1 provides group descriptive statistics for the between-subjects MANOVAs, including status (i.e., physicians and resident physicians) and self-regulation capacity (i.e., high and low).

\section{Psychological well-being}

The 2 (self-regulation capacity) X 2 (status) between subjects MANOVA with the six SPWB scales as dependent variables tested the hypothesis that psychological well-being would differ as a function of self-regulation capacity. Results showed a significant main effect of self-regulation capacity $F(6,89)=8.009, p<.001$; Pillai's Trace $=.351$, partial $\eta^{2}=.351$, but not of status, $F(6,89)=.957, p=.459$; Pillai's Trace $=.061$, partial $\eta^{2}=.061$. There was, however, an interaction effect between self-regulation capacity and status, $F(6,89)=2.852, p<.014$; Pillai's Trace $=.161$, partial $\eta^{2}=.161$. Given the significant between group differences of self-regulation capacity, and the interaction effect of selfregulation capacity and status, post-hoc univariate analyses were conducted.

First, between-subjects analyses for self-regulation capacity, using a Bonferroni adjustment of $p<.0083$, revealed that there were statistically significant univariate differences between high and low self-regulation capacity for all six scales of psychological well-being: autonomy, $F(1,94)=8.764, p<.0083, \eta^{2}=.085$; environmental mastery, $F(1,94)=27.959, p<.0083, \eta^{2}=.229$; personal growth, $F(1,94)=17.917, p<.0083$, $\eta^{2}=.160$; positive relations with others, $F(1,94)=13.553, p<.0083, \eta^{2}=.126$; purpose in life, $F(1,94)=33.911, p<.0083, \eta^{2}=.265$, and self-acceptance $F(1,94)=10.832$, $p<.0083, \eta^{2}=.103$. All $\eta^{2}$ values indicated that self-regulation capacity had an effect size ranging from medium (e.g., .085; autonomy) to large (e.g., .265; purpose in life) (Cohen 1988) across the six scales of psychological well-being.

Follow-up, pairwise comparisons supported the initial hypothesis, revealing that physicians and resident physicians with high self-regulation capacity $(n=53)$ reported significantly higher levels of psychological well-being on all six scales than those with low self-regulation capacity $(n=45)$, at $p<.0083$ : Personal growth (high, $M=71.60$, $S D=6.67$; low, $M=64.84, S D=7.16$ ); purpose in life (high, $M=73.43, S D=6.54$; low, $M=62.62$, $S D=9.09$ ); positive relations with others (high, $M=70.74, S D=9.24$; low, $M=61.80, S D=10.95$ ); self-acceptance (high, $M=69.36, S D=9.59$; low, $M=59.89$, $S D=10.95$ ); autonomy (high, $M=63.02, S D=9.31$; low, $M=56.27$; $S D=6.77$ ); and environmental mastery (high, $M=64.38, S D=8.87$; low, $M=53.53$; $S D=9.63$ ). 
Despite a significant interaction effect of self-regulation capacity and status, post-hoc between-subjects analyses did not support this as there were no statistically significant univariate differences in autonomy, environmental mastery, personal growth, positive relations with others, and purpose in life levels. However, there was a significant difference in the interaction effect for self-regulation capacity and status on the self-acceptance dimension of psychological well-being, $F(1,94)=4.601, p=.035, \eta^{2}=.047$. Upon visual inspection of the confidence interval plot (see Figure 1), the interaction did indeed appear to be significant.

Pairwise comparisons revealed that high self-regulating resident physicians possessed significantly higher levels of self-acceptance $(M=70.56 ; S D=8.61)$ than low-selfregulating resident physicians $(M=58.21 ; S D=10.1)$, while by contrast, high selfregulating physicians had only slightly higher levels of self-acceptance $(M=65.25 ; S D=$ 11.91) than their low self-regulating counterparts $(M=62.65 ; S D=12.02)$. Thus, based on the visual and pairwise comparison data, this suggests that the interaction of selfregulation capacity and status on self-acceptance appears to apply only to resident physicians. It is important to note that although significant at $.05(p=.035)$, this interaction must be interpreted with caution and more studies must confirm this before drawing valid conclusions.

\section{Affective well-being}

A second, 2 (self-regulation capacity) X 2 (status) between subjects MANOVA with the two subscales of the PANAS (positive and negative affect) as dependent variables tested the hypothesis that affective well-being would differ as a function of self-regulation capacity and status. Specifically, it was hypothesized that physicians and resident physicians reporting a higher level of self-regulation capacity would have a higher level of positive affect and a lower level of negative affect. Results showed a significant main effect of self-regulation capacity (high, $n=45$; low, $n=51), F(2,91)=4.802, p<.001$; Pillai's Trace $=.095, \eta^{2}=.095$, but no significant main effect for status (physician, $n=29$;

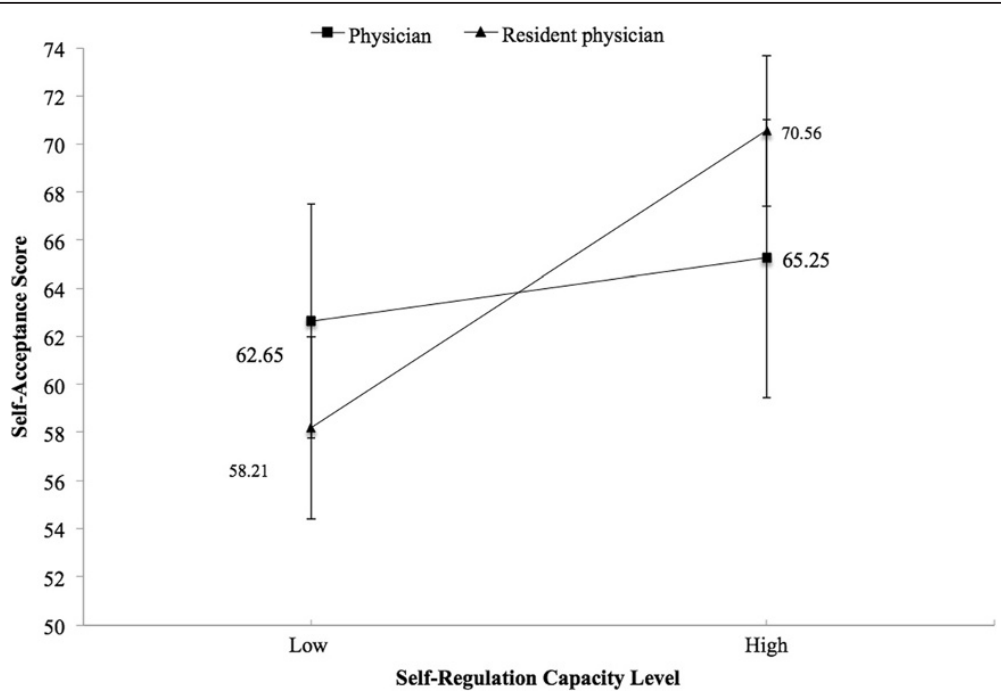

Figure 1 Interaction between self-regulation capacity level and status for self-acceptance dimension of psychological well-being. Note. Whisker bars represent the upper and lower bound confidence intervals (95\%) for mean values of low and high self-regulation capacity groups. 
resident physician, $n=67), F(2,91)=1.059, p=.351$; Pillai's Trace $=.023, \eta^{2}=.023$. The interaction effect of self-regulation capacity and status was also non significant, $F$ (2, $91)=2.652, p=.076$; Pillai's Trace $=.055, \eta^{2}=.055$. Although significant, the main effect of self-regulation capacity for affective well-being generated a relatively moderate effect size (.095) compared to the high effect size reported for psychological wellbeing (.351; based on an aggregate score of all six mean scale scores) (Cohen 1988).

Post-hoc, between-subjects analyses for self-regulation capacity, using a Bonferroni adjustment of $p<.025$, revealed that there were statistically significant univariate differences between high and low self-regulation capacity for the positive affect subscale, $F(1,92)=9.458, p<.025, \eta^{2}=.093$, but not for the negative affect subscale, $F(1,92)=$ 2.352, $p=.129, \eta^{2}=.025$. The relatively moderate effect size (Cohen 1988) suggests that $9.3 \%$ of the changes in positive affect can be accounted for by self-regulation capacity. Follow-up, pairwise comparisons revealed that physicians and resident physicians with a high level of self-regulation capacity reported significantly higher levels of positive affect $(M=36.75 ; S D=7.98)$ than those with a lower level $(M=29.69 ; S D=8.28)$, $p<.05$.

Data screening tests revealed that the assumption of homogeneity of covariance was upheld for each MANOVA, and Box's tests for equality of covariance matrices revealed no significant differences in variability between SSRQ scores and both the SPWB scale scores, $F(63,6309)=.808, p=.862$, and the PANAS subscale scores, $F(9,16171)=.322$, $p=.968$. Levene's Tests also showed homogeneity of variances $(p>.05)$ for the SPWB and the PANAS.

\section{Discussion}

The purpose of this study was to (a) assess the level of self-regulation capacity and psychological and affective well-being of physicians and resident physicians; and (b) determine if there were significant differences in psychological and affective well-being between physicians and resident physicians with high and low self-regulation capacity.

\section{Levels of self-regulation capacity and psychological and affective well-being}

With regards to the first objective, physicians and resident physicians reported moderate and high levels of self-regulation capacity, respectively (Brown et al. 1999). This suggests that both groups appear to be able to effectively manage themselves in their dynamic and demanding medical environment by enacting a network of processes such as goal setting and proactive planning, self-monitoring, and self-evaluation (Bandura 1991; Zimmerman 2000). These results are similar to those of Gagnon and DurandBush (2012) who examined the self-regulation capacity of medical students and physicians. Given that effective self-management skills have been found to positively impact productivity and work performance, mental and physical health, and the quality of social relationships (Diener and Biswas-Diener 2008; Keyes and Waterman 2003), the current findings are promising.

Furthermore, self-regulation capacity involves the development of self-awareness and self-reflection, and studies in the medical context have demonstrated that nurturing such attributes can help physicians maintain a more satisfying balance between their professional and personal life (Novack et al. 1997). Moreover, self-care activities and 
effective coping skills are associated with lower levels of burnout (Eckleberry-Hunt et al. 2009). This is especially relevant for resident physicians given that the pressures of medical training are very high (Cohen and Patten 2005), and these individuals are also more likely to experience burnout compared to their trained physician counterparts (Leiter et al. 2009). Overall, with the consistently growing demands of the medical profession (Gautam 2009), it is not surprising that physicians and resident physicians possess reasonably effective self-regulation capacity and show adaptability in order to be able to fulfill their role as key health service providers.

At first glance, the high levels of psychological well-being reported by the physicians and resident physicians appear to contradict conventional wisdom and research showing that they experience a high prevalence of negative psychological outcomes such as burnout (Wallace and Lemaire 2007), stress and anxiety (Cohen and Patten 2005), and depression (Gardiner et al. 2004). However, it is important to emphasize that the present study focused on indicators of positive psychological functioning and not negative outcomes. Thus one cannot ascertain if the participants were experiencing a high level of well-being even in the presence of high anxiety and burnout symptoms (e.g., Keyes, 2002).

Like self-regulation capacity, there are few studies in the medical context that offer comparative data for psychological well-being. However, Gagnon and Durand-Bush (2012) found similar results in that both physicians and medical students in their study reported moderate to moderately high levels of psychological well-being, with personal growth, positive relationships, and purpose in life generating the highest scores. Interestingly, the physicians and resident physicians in the current study also scored the highest on personal growth and purpose in life (relative to the other scales). According to Ryff and Keyes (1995), personal growth involves continued development, especially as it relates to increasing self-knowledge and effectiveness. Ongoing professional development such as learning how to determine personal needs and desired outcomes is an important part of medicine (Mann and Gelula 2003; Violato and Lockyer 2006). Furthermore, many medical licensing boards make it compulsory for their members to participate in continuing education programs in order to maintain their professional certification (Duffy and Holmboe 2006). As such, it is not particularly surprising that personal growth was rated as high among participants in the current study and that of Gagnon and Durand-Bush (2012). Participants also reported a strong sense of purpose in life, which is a key aspect of optimal functioning. This suggests that the physicians and resident physicians had goals and a sense of directedness, and they felt that there was meaning to their present and past life (Ryff and Keyes 1995). According to Devi (2011), individuals should choose a medical career based on personal values and aims, and it appears that those in the current study valued their work. Interestingly, value congruence has been shown to be a strong predictor of professional efficacy and lower levels of distress (Leiter et al. 2009). As such, there seems to be merit in nurturing a strong sense of purpose and values in physicians.

Although the physicians and resident physicians in this study reported high levels of autonomy and moderate to high levels of environmental mastery, these were lower relative to the other dimensions. Since environmental mastery is associated with a sense of competence in managing the activities within one's environment (Ryff and Keyes 1995), it is somewhat interesting that despite the years of intensive medical training that physicians undergo, they rated this dimension of psychological well-being as one of the lowest. 
A potential explanation could be that physicians today face consistently growing demands and pressures and perceive to have less control over their environment, the effect of which is compounded by decreasing personal and occupational resources (Gautam 2009).

The physicians and resident physicians reported moderate levels of both positive and negative affect. These findings are consistent with data from the general population (e.g., Foster et al. 2008) but inconsistent with some previous research suggesting there is a high prevalence of emotional distress among physicians (Ro et al. 2007). However, since the present study is the first known one to assess the affective well-being of physicians using the PANAS, more research is warranted to confirm this finding. It is important to develop a comprehensive understanding of the positive and negative affect levels of physicians as there are potentially serious consequences if physicians experience distress and emotionally disconnect themselves from their work (Meldrum 2010), one of which is burnout (Tyssen 2007).

Differences in psychological and affective well-being as a function of self-regulation capacity Results of this study confirmed the hypothesis that high self-regulating physicians and resident physicians would have higher levels of psychological well-being and positive affect compared to those with lower levels of self-regulation capacity. These results are consistent with the literature on the concept of self-regulation and Gagnon and Durand-Bush (2012) findings. Effective self-regulation leads to a range of positive well-being outcomes (Baumeister et al. 2006; Sanders and Mazzucchelli 2012), and interestingly, individuals with higher levels of well-being tend to adopt more positive self-care behaviours, and exhibit fewer maladaptive behaviours (Diener and Ryan 2009; Zimmerman 2000). Of interest, self-regulation capacity does not necessarily develop with maturation; it can and should be nurtured by external social agents (Zimmerman 2000). Simon and DurandBush (2009) found that nurturing self-regulation capacity in medical students through a 17-week intervention was perceived to enhance performance and well-being. As such, it would be worthwhile to further investigate if and how the development of self-regulation skills can increase physician and resident physicians' well-being.

The finding that physicians and resident physicians with high levels of self-regulation capacity also reported higher levels of positive affect than their lower self-regulating colleagues emphasizes the role of emotions in the self-regulation process (Gross and Thompson 2007). For instance, emotions are thought to contribute to both successes and failures of self-regulation (Vohs and Baumeister 2004), and are essential for our continuing mental and physical health (Ochsner and Gross 2004). In the context of medicine, emotions are linked to physician well-being, especially with respect to negative outcomes such as anxiety (Ro et al. 2007). However, results of this study did not support the hypothesis that higher self-regulating individuals would have lower negative affect. Perhaps this is an indication that even though the physicians and resident physicians could selfmanage, they still experienced some negative affect due to the demands and stressors they encountered in the profession. More research is required to confirm this finding.

\section{Differences in psychological and affective well-being as a function of status}

Although findings did not support the hypothesis that physicians would have significantly higher levels of psychological and affective well-being than resident physicians, there was 
tentative support for an interaction between self-regulation capacity and status for the self-acceptance dimension of psychological well-being. In other words, high selfregulating resident physicians possessed significantly higher levels of self-acceptance than their low-self-regulating counterparts, while high self-regulating physicians had only slightly higher levels of self-acceptance than their low self-regulating colleagues. The absence of overall differences between the two groups is not inconsistent with existing findings. For example, dysfunctional outcomes such as burnout (Bragard et al. 2010), stress (Daly and Willcock 2002), and anxiety (Michels et al. 2003) have not only been reported in physicians but also resident physicians. However, it is unclear as to why self-regulation capacity would have a higher impact on the self-acceptance of resident physicians. Selfacceptance is characterized by positive evaluations and a positive attitude toward oneself and past life experiences (Ryff and Keyes 1995). One possible explanation is that residents who can effectively manage their thoughts, feelings, and behaviors in their personal and professional life may be more inclined to accept the different roles they play and be more satisfied with themselves and their past experiences, even though they have less practice than physicians who have been in the field for a while. Conversely, more skilled physicians may need to rely less on their capacity to self-regulate in order to maintain positive selfevaluations and an overall sense of satisfaction with their life.

\section{Limitations}

Although the results of this study offer unique insight into the role that self-regulation capacity may play in the well-being of physicians, there are several notable limitations. First, given the nature of self-reported data and the potential effect of social desirability, results must be interpreted with caution (McBurney 1994). Furthermore, even though most geographical regions of Canada were represented, participation rates were disproportionate and results should not be generalized to all physicians.

There are also limitations with respect to the measures used. First, the PANAS measured how participants felt over "the last few days" (Watson et al. 1988), whereas questions from the SSRQ (Carey et al. 2004) and the SPWB (Ryff and Keyes 1995) pertained to general perceptions of self-regulation capacity and psychological well-being over a longer period of time (e.g., weeks or months). Therefore, the fact that responses were based on different temporal periods makes it more difficult to compare results. Second, the SSRQ and SPWB could be considered as "trait" rather than "state" self-report measures. However, one could argue that self-regulation capacity and psychological well-being may be context specific, and the SSRQ and SPWB do not assess potential variations across contexts. An important step to advance research would be to explore the dynamic and contextual aspects of both self-regulation capacity and well-being and ensure that measures account for any potential variation. With respect to the SSRQ, although an EFA supported the 19-item version that was used for the analyses, further psychometric tests with this shorter version are advised. While the SSRQ was the most reliable and conceptually relevant measure available, the complex and dynamic nature of selfregulation capacity may warrant the development of a more comprehensive tool. Finally, the significant interaction between self-regulation capacity and status for the dimension of self-acceptance must be interpreted with caution as an unadjusted significance level $(p<.05)$ was used to determine significance and the effect size was small (Cohen 1988). 


\section{Conclusions}

In light of calls for research emphasizing the positive elements of physician well-being (Spickard 2001), the present study addressed an important gap in the literature. Building on the findings of Gagnon and Durand-Bush (2012), Sandars and Cleary (2011), and Simon and Durand-Bush (2009), results suggest that a deeper understanding of physicians' capacity to self-regulate could help uncover ways to help them achieve positive and healthy living (Shanafelt et al. 2003). Physicians and resident physicians in this study had moderate to high levels of self-regulation capacity. They also reported moderate to high levels of psychological and affective well-being. Of interest, high selfregulating physicians and resident physicians possessed higher levels of psychological well-being and positive affect compared to their low self-regulating colleagues, however, there were no differences with regards to negative affect.

As a fundamental capacity and important element of positive human functioning, self-regulation capacity has a profound impact on everyday living (Vohs and Baumeister 2004). Given the positive link between the participants' capacity to self-regulate and their levels of well-being, and the lack of significant differences between the levels of physicians and resident physicians, the present study suggests that developing or strengthening self-regulation competence could be a potential avenue to help both physicians and resident physicians become adaptive and resilient to the evolving demands of the medical profession (Remen 2001).

\section{Endnotes}

${ }^{a}$ Mean scores greater than or equal to 71.5 represent high self-regulation capacity; mean scores between 71 and 65 reflect moderate capacity; and less than or equal to 64.5 scores show low self-regulation capacity

${ }^{\mathrm{b}}$ High scores are those greater than 59.5; moderate-high scores are between 35 and 59.5; moderate-low scores are between 24.5 and 35; and low scores are lower than 24.5

${ }^{\mathrm{c}}$ Mean scores greater than or equal to 35 represent above average to very high positive affect, while mean scores between 32 and 34 represent average, and less than or equal to 31 reflect below average to very low positive affect. With respect to negative affect, mean scores greater than or equal to 31 represent above average to very high negative affect, while mean scores between 20 and 30 represent average, and less than or equal to 15 reflect below average to very low negative affect.

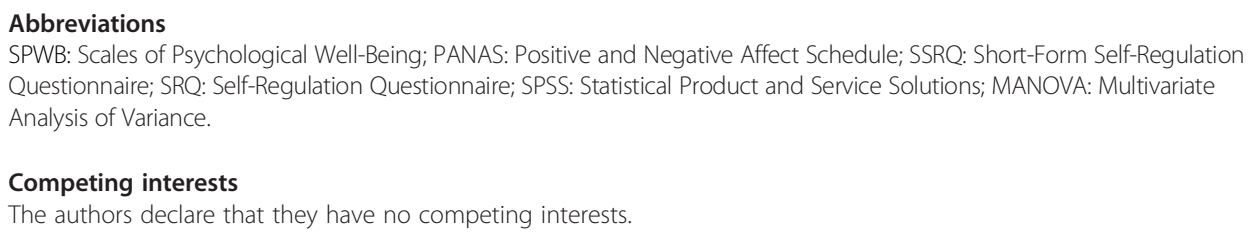

Baumeister, RF, Gailliot, M, DeWall, CN, \& Oaten, M. (2006). Self-regulation and personality: How interventions increase regulatory success and how depletion moderates the effects of traits on behavior. Journal of Personality, 74(6), 1773-1802. 
Biaggi, P, Peter, S, \& Ulich, E. (2003). Stressors, emotional exhaustion and aversion to patients in residents and chief residents - what can be done? Swiss Medical Weekly, 133, 339-346.

Boekaerts, M, \& Niemivirta, M. (2000). Self-Regulated Learning: Finding a Balance Between Learning Goals and ego-Protective Goals. In M Boekaerts, PR Pintrich, \& M Zeidner (Eds.), Handbook of Self-Regulation (pp. 417-446). San-Diego, CA: Academic.

Bragard, I, Etienne, AM, Merckaert, I, Libert, Y, \& Razavi, D. (2010). Efficacy of a communication and stress management training on medical residents' self-efficacy, stress to communicate and burnout: a randomized controlled study. Journal of Health Psychology, 15(7), 1075-1081.

Brown, JM. (1998). Self-Regulation and the Addictive Behaviors. In WR Miller \& N Heather (Eds.), Treating Addictive Behaviors (2nd ed., pp. 61-73). New York, NY: Plenum.

Brown, JM, Miller, WR, \& Lawendowski, LA. (1999). The Self-Regulation Questionnaire. In L VandeCreek \& TL Jackson (Eds.), Innovations in Clinical Practice: A Source Book (Vol. 17, pp. 281-292). Sarasota, FL: Professional Resource Press/ Professional Resource Exchange.

Brunstein, JC. (1993). Personal goals and subjective well-being: a longitudinal study. Journal of Personality and Social Psychology, 65, 1061-1070.

Carey, KB, Neal, DJ, \& Collins, SE. (2004). A psychometric analysis of the self-regulation questionnaire. Addictive Behaviors, $29,253-260$.

Carmody, J, \& Baer, RA. (2008). Relationships between mindfulness practice and levels of mindfulness, medical and psychological symptoms and well-being in a mindfulness-based stress reduction program. Journal of Behavioral Medicine, 31, 23-33.

Carver, CS, \& Scheier, MF. (1998). On the Self-Regulation of Behavior. New York, NY: Cambridge University Press.

Cerny, CA, \& Kaiser, HF. (1977). A study of a measure of sampling adequacy for factor-analytic correlation matrices. Multivariate Behavioral Research, 12(1), 43-47.

Cohen, J. (1988). Statistical Power Analysis for the Behavioral Sciences (2nd ed.). Hillsdale, NJ: Lawrence Erlbaum Associates.

Cohen, JS, \& Patten, S. (2005). Well-being in residency training: a survey examining resident physician satisfaction both within and outside of residency training and mental health in Alberta. BMC Medical Education, 5(21), 1-11.

Compton, WC. (2005). An Introduction to Positive Psychology. Belmont, CA: Thomson-Wadsworth.

Daly, MG, \& Willcock, SM. (2002). Examining stress and responses to stress in medical students and new medical graduates. Medical Journal of Australia, 177, 14-15.

Devi, S. (2011). Doctors in distress. The Lancet, 337, 454-455.

Diener, E. (1984). Subjective well-being. Psychological Bulletin, 95, 542-575.

Diener, E, \& Biswas-Diener, R. (2008). Happiness: Unlocking the Mysteries of Psychological Wealth. Malden, MA: Blackwell Publishing.

Diener, E, \& Ryan, K. (2009). Subjective well-being: an overview. South African Journal of Psychology, 39(4), 391-406.

Diez-Pinol, M, Dolan, SL, Sierra, V, \& Cannings, K. (2008). Personal and organizational determinants of well-being at work: the case of Swedish physicians. International Journal of Health Care Quality Assurance, 21(6), 598-610.

Duffy, DF, \& Holmboe, ES. (2006). Self-assessment in lifelong learning and improving performance in practice: Physician know thyself. Journal of the American Medical Association, 296(9), 1137-1139.

Dukes-Holland, K, \& Holahan, CK. (2003). The relation of social support and coping to positive adaptation to breast cancer. Psychology and Health, 18(1), 15-29.

Eckleberry-Hunt, J, Lick, D, Boura, J, Hunt, R, Balasubramaniam, M, Mulhem, E, \& Fisher, C. (2009). An exploratory study of resident burnout and wellness. Academic Medicine, 84(2), 269-277.

Firth-Cozens, J, \& Greenhalgh, J. (1997). Doctors' perceptions of the links between stress and lowered clinical care. Social Science and Medicine, 44, 1017-1022.

Foster, JM, Sanderman, R, van der Molen, T, Mueller, T, \& van Sonderen, E. (2008). Personality influences the reporting of side effects of inhaled corticosteroids in asthma patients. Journal of Asthma, 45, 664-669.

Gagnon, M, \& Durand-Bush, N. (2012). The Relationship Between Self-Regulation, Psychological Well-Being, Psychological Stress, and Burnout in a High-Pressure Performing Context: What we can Learn from Physicians and Medical Students? Honolulu, HI, USA: Paper presented at annual North American Society for the Psychology of Sport and Physical Activity Conference.

Gardiner, M, Lovell, G, \& Williamson, P. (2004). Physician you can heal yourself! Cognitive behavioural training reduces stress in GPs. Family Practice, 21(5), 545-551.

Garson, GD. (2012). Multiple Regression Analysis: How big a Sample Size do I Need?: StatNotes: Online textbook in statistics. http://faculty.chass.ncsu.edu/garson/PA765/regress.htm\#samplesize. Accessed on March, 2012.

Gautam, M. (2009). Physician Health Becomes a Global Movement. (Report from the 2008 International Conference on Physician Health). Ottawa, ON: Canadian Medical Association Press.

George, D, \& Mallery, P. (2003). SPSS for Windows Step by Step: A Simple Guide and Reference (4th ed.). Boston, MA: Allyn \& Bacon.

Goldman, LS, Myers, M, \& Dickstein, LJ. (2000). The Handbook of Physician Health: The Essential Guide to Understanding the Health Care Needs of Physicians. Chicago, II: AMA Press.

Gross, JJ, \& Thompson, RA. (2007). Emotion Regulation: Conceptual Foundations. In JJ Gross (Ed.), Handbook of Emotion Regulation (pp. 3-24). New York, NY: The Guilford Press.

Haworth, J, \& Hart, G. (2007). Introduction. In J Haworth \& G Hart (Eds.), Well-Being: Individual, Community, and Social Perspectives (pp. 1-25). New York, NY: Palgrave Macmillan.

Hofer, J, Busch, H, \& Kartner, J. (2011). Self-regulation and well-being: The influence of identity and motives. European Journal of Personality, 25, 211-224.

Hustad, JTP, Carey, KB, Carey, MP, \& Maisto, SA. (2009). Self-regulation, alcohol consumption, and consequences in collegestudent heavy drinkers: a simultaneous latent growth analysis. Journal of Studies on Alcohol and Drugs, 70(3), 373-382.

Keyes, CLM. (2002). The mental health continuum: from languishing to flourishing in life. Journal of Health and Social Behavior, 43(2), 207-222.

Keyes, CLM, \& Waterman, MB. (2003). Dimensions of Well-Being and Mental Health in Adulthood. In MH Bornstein, L Davidson, CLM Keyes, \& CA Moore (Eds.), Well-Being: Positive Development Across the Life Course (pp. 477-495). Mahwah, N.J: Lawrence Erlbaum Associates. 
Krasner, MS, Epstein, RM, Beckman, H, Suchman, AL, Chapman, B, Mooney, CJ, \& Quill, TL. (2009). Association of an educational program in mindful communication with burnout, empathy, and attitudes among primary care physicians. Journal of the American Medical Association, 302(12), 1284-1293.

Leiter, MP, Frank, E, \& Matheson, TJ. (2009). Demands, values \& burnout. Canadian Family Physician, 55(12), 1224-1225.

Lent, RW, \& Brown, SD. (2008). Social cognitive career theory and subjective well-being in the context of work. Journal of Career Assessment, 16, 6-21.

Leventhal, H, Brissette, I, \& Leventhal, EA. (2003). The Common-Sense Model of Health and IIlness Behavior. In LD Cameron \& H Leventhal (Eds.), The Self-Regulation of Health and IIIness Behavior (pp. 42-66). New York, NY: Routledge.

Leventhal, H, Leventhal, EA, \& Contrada, R. (1998). Self-regulation health, and behaviour: a perceptual-cognitive approach. Psychology and Health, 13, 717-733.

Mann, KV, \& Gelula, MH. (2003). How to Facilitate Self-Directed Learning. In D Davis, BE Barnes, \& R Fox (Eds.) The Continuing Development of Physicians (pp. 121-143). Chicago, II: AMA Press.

McBurney, DH. (1994). Research Methods. Pacific Grove, CA: Brooks/Cole.

Meldrum, H. (2010). Exemplary physicians' strategies for avoiding burnout. The Health Care Manager, 29(4), 324-331.

Michels, PJ, Probst, JC, Godenick, MT, \& Palesch, Y. (2003). Anxiety and anger among family practice residents: a South Carolina family practice research consortium study. Academic Medicine, 78, 69-79.

Miller, BM, Bartholomew, JB, \& Springer, BA. (2005). Post exercise affect: the effect of mode preference. Journal of Applied Sport Psychology, 17, 263-272.

Miller, WR, \& Brown, JM. (1991). Self-Regulation as a Conceptual Basis for the Prevention and Treatment of Addictive Behaviors. In N Heather, WR Miller, \& J Greenley (Eds.), Self Control and the Addictive Behaviors (pp. 3-79). Sydney, Australia: Maxwell Macmillan.

Musselman, L. (2003). A Resident's Perspective on Well-Being. In M Myers (Ed.), Canadian Medical Association Guide to Physician Health and Well-Being: Facts, Advice and Resources for Canadian Doctors (pp. 13-15). Ottawa, ON: Canadian Medical Association.

Novack, DH, Suchman, AL, Clark, W, Epstein, RM, Najberg, E, \& Kaplan, C. (1997). Calibrating the physician: personal awareness and effective patient care. Journal of the American Medical Association, 278(6), 502-509.

Ochsner, KN, \& Gross, J. (2004). Thinking Makes it so: A Social Cognitive Neuroscience Approach to Emotion Regulation. In RF Baumeister \& KD Vohs (Eds.), Handbook of Self-Regulation: Research, Theory, and Applications (pp. 229-255). New York, NY: The Guilford Press.

Okun, MA, Levy, R, Karoly, P, \& RuehIman, L. (2009). Dispositional happiness and college student GPA: Unpacking a null relation. Journal of Research in Personality, 43, 711-715.

Park, CL, Edmondson, D, \& Lee, J. (2012). Development of self-regulation abilities as predictors of psychological adjustment across the first year of college. Journal of Adult Development, 19, 40-49.

Parker, SJ, Strath, SJ, \& Swartz, AM. (2008). Physical activity measurement in older adults: Relationships with mental health. Journal of Aging and Physical Activity, 16(4), 369-380.

Peeters, FPML, Ponds, RWHM, \& Vermeeren, MTG. (1996). Affectivitieit en zelfbeoordeling van depressie en angst [Affectivity and self-report of depression and anxiety]. Tijdschrift voor Psychiatrie, 39, 240-250.

Remen, RN. (2001). Recapturing the soul of medicine: physicians need to reclaim meaning in their working lives. Western Journal of Medicine, 174, 4-5.

Riediger, M, \& Freund, AM. (2004). Interference and facilitation among personal goals: differential associations with subjective well-being and persistent goal pursuit. Personality and Social Psychology Bulletin, 30, 1511-1523.

Ro, KE, Gude, T, \& Aasland, OG. (2007). Does a self-referral counselling program reach doctors in need of help? A comparison with the general Norwegian doctor workforce. BMC Public Health, 7(36), 1-8.

Rosen, IM, Gimotty, PA, Shea, JA, \& Bellini, LM. (2006). Evolution of sleep quantity, sleep deprivation, mood disturbances, empathy and burnout amongst interns. Academic Medicine, 81(1), 82-85.

Ryff, CD. (1989). Happiness is everything, or is it? Explorations on the meaning of psychological well-being. Journal of Personality and Social Psychology, 57, 1069-1081.

Ryff, CD, \& Keyes, CLM. (1995). The structure of psychological well-being revisited. Journal of Personality and Social Psychology, 69, 719-719.

Sandars, J, \& Cleary, TJ. (2011). Self-regulation theory: applications to medical education. Medical Teacher, 33(11), 875-886.

Sanders, MR, \& Mazzucchelli, TG. (2012). The Promotion of Self-Regulation Through Parenting Interventions. In V Barkoukis (Ed.), Psychology of Self-Regulation (pp. 103-119). New York, NY: Nova.

Seligman, ME, \& Csikszentmihalyi, M. (2000). Positive psychology: an introduction. American Psychologist, 55(1), 5-14.

Shanafelt, TD. (2008). A career in surgical oncology: finding meaning, balance, and personal satisfaction. Annals of Surgical Oncology, 15(2), 400-406.

Shanafelt, TD, Bradley, KA, Wipf, JE, \& Back, AL. (2002). Burnout and self-reported patient care in an internal medicine residency program. Annals of Internal Medicine, 136, 358-367.

Shanafelt, TD, Sloan, J, \& Habermann, TM. (2003). The well-being of physicians. The American Journal of Medicine, 114, 513-517.

Shanafelt, TD, West, C, Zhao, X, Novotny, P, Kolars, J, Habermann, T, \& Sloan, J. (2005). Relationship between increased personal well-being and enhanced empathy among internal medicine residents. Journal of General Internal Medicine, 20, 559-564.

Simon, CR, \& Durand-Bush, N. (2009). Learning to self-regulate multi-dimensional felt experiences: the cases of four female medical students. International Journal of Qualitative Studies on Health and Well-Being, 4(4), 228-244.

Spickard, A. (2001). What do we know about physician well-being? Western Journal of Medicine, 174, 23-24.

Strauser, DR, Lustig, DC, \& Ciftci, A. (2008). Psychological well-being: its relation to work personality, vocational identity, and career thoughts. The Journal of Psychology, 142(1), 21-35.

Tabachnick, BG, \& Fidell, LS. (1996). Using Multivariate Statistics (4th ed.). Boston, MA: Pearson.

Tangney, JP, Baumeister, RF, \& Boone, AL. (2004). High self-control predicts good adjustment, less pathology, better grades, and interpersonal success. Journal of Personality, 72, 271-324. 
Taub, S, Morin, K, Goldrich, PR, \& Benjamin, R. (2006). Physician health and wellness. Occupational Medicine, 56, 77-82. Thomas, NK. (2004). Resident burnout. JAMA, 292(23), 2880-2889.

Tyssen, R. (2007). Health problems and the use of health services among physicians: a review article with particular emphasis on Norwegian studies. Industrial Health, 45, 599-610.

Uncu, Y, Bayram, N, \& Bilgel, N. (2006). Job related affective well-being among primary health care physicians. European Journal of Public Health, 17(5), 514-519.

Violato, C, \& Lockyer, J. (2006). Self and peer assessment of pediatricians, psychiatrists, and medicine specialists: Implications for self-directed learning. Advances in Health Sciences Education, 11, 235-244.

Vohs, KD, \& Baumeister, RF. (2004). Understanding Self-Regulation: An Introduction. In RF Baumeister \& KD Vohs (Eds.), Handbook of Self-Regulation: Research, Theory, and Applications (pp. 1-12). New York, NY: The Guilford Press.

Voogt, E, van der Heide, A, van Leeuwen, AF, Visser, AP, Cleiren, MP, Passchier, J, \& van der Maas, PJ. (2005). Positive and negative affect after diagnosis of advanced cancer. Psychooncology, 14(4), 262-273.

Wallace, JE, \& Lemaire, J. (2007). On physician well being: You'll get by with a little help from your friends. Social Science \& Medicine, 6, 2565-2577.

Watson, D, Clark, LA, \& Tellegen, A. (1988). Development and validation of brief measures of positive and negative affect: the PANAS scales. Journal of Personality and Social Psychology, 54, 1063-1070.

Weiner, EL, Swain, GR, Wolf, B, \& Gottlieb, M. (2001). A qualitative study of physicians' own wellness-promotion practices. Western Journal of Medicine, 174, 19-23.

Williams, ES, Konrad, TR, Linzer, M, McMurray, J, Pathman, DE, Gerrity, M, Schwartz, MD, Scheckler, WE, \& Douglas, D. (2002). Physician, practice, and patient characteristics related to primary care physician physical and mental health: Results from the Physician Worklife Study. Health Services Research, 37(1), 121-143.

Zimmerman, BJ. (2000). Attaining Self-Regulation: A Social-Cognitive Perspective. In M Boekaerts, PR Pintrich, \& M Zeidner (Eds.), Handbook of Self-Regulation (pp. 13-42). San-Diego, CA: Academic.

doi:10.1186/s13612-014-0019-2

Cite this article as: Simon and Durand-Bush: Differences in psychological and affective well-being between

physicians and resident physicians: Does high and low self-regulation capacity matter? Psychology of Well-Being: Theory, Research and Practice 2014 4:19.

\section{Submit your manuscript to a SpringerOpen ${ }^{\circ}$} journal and benefit from:

- Convenient online submission

- Rigorous peer review

- Immediate publication on acceptance

- Open access: articles freely available online

- High visibility within the field

- Retaining the copyright to your article

Submit your next manuscript at $\boldsymbol{\sim}$ springeropen.com 